\title{
Continuing education: from FRCPC to ACGME fellowship
}

\author{
Farrukh Munshey, MD, FRCPC • Ban C. H. Tsui, MD, FRCPC (1)
}

Received: 26 October 2017/Revised: 16 November 2017 / Accepted: 16 November 2017/Published online: 4 December 2017

(c) Canadian Anesthesiologists' Society 2017

\section{To the Editor,}

Fellowships provide graduate residents an opportunity to master a specific set of skills, gain confidence, and receive further mentorship. ${ }^{1}$ Pursuing a fellowship in a different country can help one appreciate social, logistic, and environmental differences in clinical practice. ${ }^{2} \mathrm{~A}$ common challenge in pursuing a fellowship in another country is the application process itself. Resident trainees from Royal College of Physicians and Surgeons of Canada (RCPSC)-accredited programs considering a fellowship in the United States (US) often find the application process complicated. Using personal experience from going through the Accreditation Council for Graduate Medical Education (ACGME) Pediatric Anesthesiology Fellowship matching process this past year, we provide a simple timeline highlighting key events in the process catered towards RCPSC residents (Figure). In addition, we highlight a significant difference in residency training between the two countries and its potential implications for fellowship training.

An essential aspect of the application process is timing. Some programs begin accepting applications as early as November of a resident's fourth post-graduate year (PGY) and process applications in the order they were submitted. For ACGME anesthesia fellowships, only obstetrics, pediatrics, and pain medicine currently take part in the National Residency Matching Service, which has clearly

F. Munshey, MD, FRCPC

Department of Anesthesiology, Perioperative and Pain Medicine, Lucile Packard Children's Hospital, Palo Alto, CA, USA

B. C. H. Tsui, MD, FRCPC ( $₫)$

Department of Anesthesiology, Perioperative and Pain Medicine, School of Medicine, Stanford University, Stanford, CA, USA e-mail: bantsui@stanford.edu stated deadlines, similar to the Canadian Residency Matching Service (CaRMS). Unlike CaRMS, however, candidates who submit fellowship applications early can be offered interviews well in advance of the application deadline. Thus, it is advantageous for the candidate to apply early.

Upon a successful match, the subsequent steps include obtaining a J1 (https://j1visa.state.gov/) or H-1 B visa (https://www.uscis.gov), Social Security number, and state medical license before the start date of 1 August following residency. H1-B visa applicants require certification of the United States Medical Licensing Examinations. ${ }^{3}$ For RCPSC program graduates who are not US citizens, it is highly encouraged to arrive four weeks in advance for timely completion of the paperwork. For instance, the Medical Board of California will finalize and issue a medical license only after the candidate has physically entered the US and received a valid Social Security number.

An important difference between RCPSC vs ACGME program graduates is the timing of board examinations. Most RCPSC graduates will have completed their written and oral boards before completion of residency and, if successful, be certified as a Fellow of the Royal College of Physicians of Canada (FRCPC) prior to starting the fellowship. The ACGME graduates, in contrast, have their written boards after completing the residency. The written board for anesthesiology is in late July while the oral boards are earliest, in March, the following year. As such, most ACGME graduates will remain board eligible and prepare for their board examinations during the fellowship. The RCPSC graduates have no examination preparation and thus have the advantage of being able to focus more on the intensive educational experience. With 


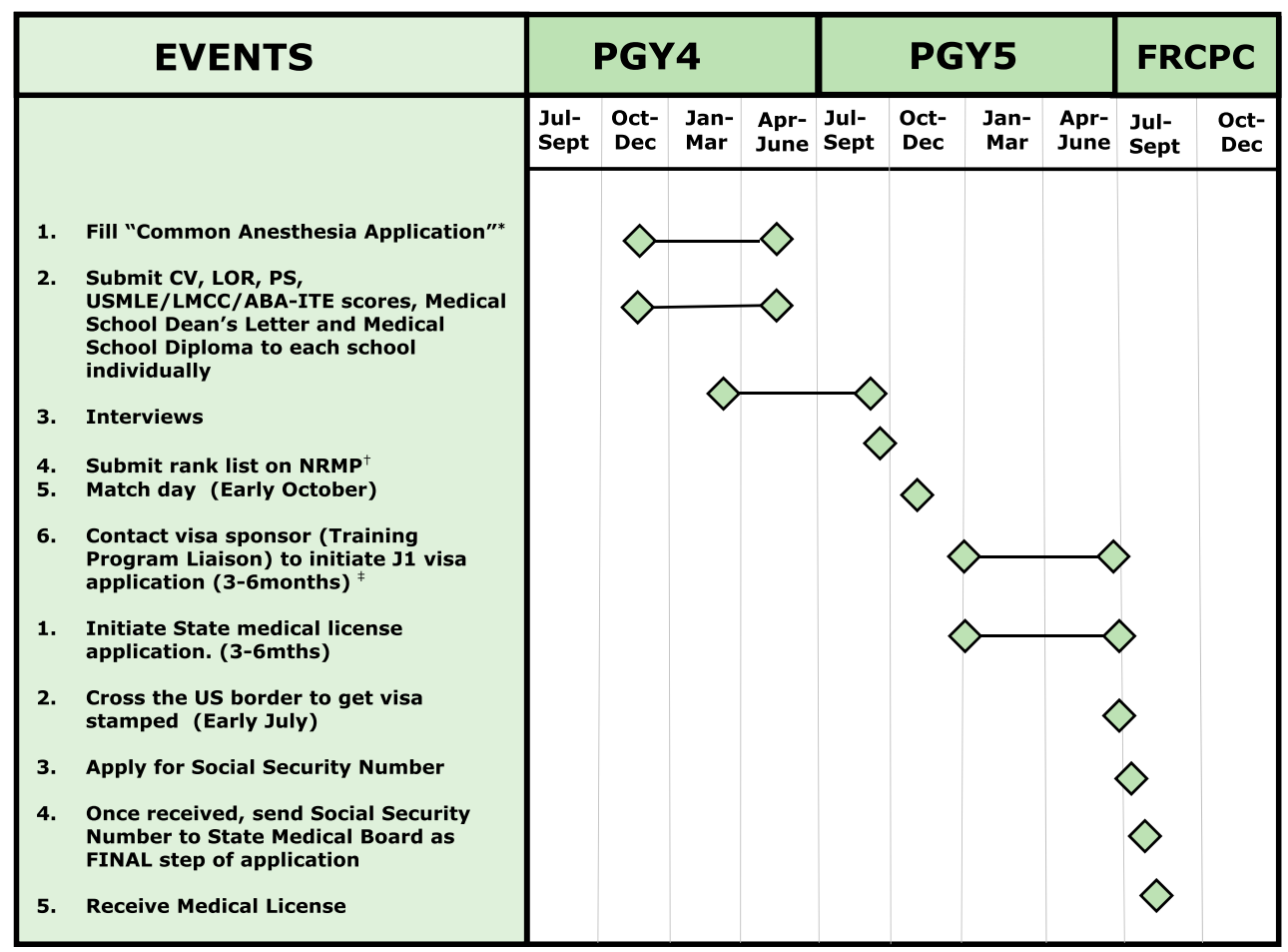

Figure Timeline for Canadian Anesthesiology Residents applying for United States Accreditation Council for Graduate Medical Education Fellowship. PGY4 = post-graduate year 4; PGY5 = postgraduate year 5; FRCPC $=$ Fellow of the Royal College of Physicians of Canada; FRCSC $=$ Fellow of The Royal College of Surgeons of Canada; $\mathrm{CV}=$ curriculum vitae, $\mathrm{LOR}=$ letters of reference; $\mathrm{PS}=$ personal statement; USMLE = United States Medical Licensing Examination; LMCC = Licensure of Medical Council of Canada, ABA-ITE $=$ American Board of Anesthesiology-in-training Examination; NRMP $=$ National Resident Matching Program.

the recent transition to a Competency by Design (CBD) curriculum in Canada, ${ }^{4}$ the RCPSC written and oral boards have moved to the fall and spring of a resident's fifth postgraduate year. A resident must pass the written boards before sitting for the oral boards in the CBD system. This change makes the difference in examination completion between the two countries even more prominent. This competency-based curriculum could, in turn, allow RCPSC residents to do subspecialty electives during the "transition to practice" phase and still apply early for ACGME US fellowships.

By appreciating the timelines, paperwork, and examination differences, we hope that RCPSC graduate residents can better prepare for the US fellowship experience. The year helps one gain confidence and maturity while simultaneously becoming a more desirable clinician in the eyes of future patients. In the end, the subspecialized clinician can return to practice with new
*Application available from https://www.aamc.org/eras; †List submitted at http://www.nrmp.org; ${ }^{*}$ Details regarding application for a JI visa available from the Educational Commission of Foreign Medical Graduates, https://oasis2.ecfmg.org. Note that a Social Security number can only be applied for after arriving in the United States and will take seven to 14 days to arrive. An email notice acknowledging approval of your medical license will be sent within three to five days of receipt of your Social Security number. An official hard copy of your license will be mailed within one to two weeks

ideas and methods based on US practice that can potentially enhance patient care in Canada.

\section{Conflicts of interest None declared.}

Editorial responsibility This submission was handled by Dr. Gregory L. Bryson, Deputy Editor-in-Chief, Canadian Journal of Anesthesia.

\section{References}

1. Grover BT, Kothari SN. Fellowship training: need and contributions. Surg Clin North Am 2016; 96: 47-57.

2. Riva $N$, Lauw MN. Benefits and challenges of going abroad for research or clinical training. J Thromb Haemost 2016; 14: 1683-4.

3. Korcok M. At least 12 US states refuse to recognize physician training accredited in Canada. CMAJ 1998; 158: 1061-3.

4. Levine $M F$, Shorten $G$. Competency-based medical education: its time has arrived. Can J Anesth 2016; 63: 802-6. 